\title{
Developments in ferroelectric ceramics for capacitor applications
}

\author{
DHANANJAI PANDEY, A P SINGH and V S TIWARI \\ School of Materials Science and Technology, Banaras Hindu University, Varanasi 221005 , \\ India

\begin{abstract}
A brief overview of the materials and processes for making ceramic capacitors based on $\mathrm{BaTiO}_{3}$ and relaxor ferroelectric compositions is presented with special emphasis on more recent developments.
\end{abstract}

Keywords. Ferroelectric ceramics; ceramic capacitors; barium titanate; relaxor ferroelectrics.

\section{Introduction}

The last few decades have witnessed an ever increasing interest in ferroelectric ceramics because of their applications in a wide range of devices. Ferroelectric ceramics possess extremely high dielectric constant which makes them unenviable for making miniaturized single- and multi-layer capacitors. The excellent electromechanical response of these ceramics, on the other hand, is currently being utilized in a large number of devices such as sonars, high voltage generators, resonators, flaw detectors, lighters, actuators and micro-positioners. When doped with suitable off-valent cations, these ceramics exhibit semiconducting behaviour. In such semiconducting ferroelectric ceramics, the interaction of electrical transport with ferroelectricity near Curie point leads to nonlinear positive temperature coefficient of resistance (PTCR-effect) which is being commercially exploited in PTC-thermistors. The pyroelectric and electro-optic properties of these ceramics are no less interesting. These properties, however, have not been as much commercially exploited as the other properties mentioned earlier. Potential applications envisaged are in IR imaging and detection, goggles for avoiding flash-blindness, optical displays and optical modulations. The remanence behaviour has been shown recently to be useful for non-volatile RAM cells operating at a few volts.

As a result of intensive research activity, the topic of ferroelectric ceramics has acquired the level of a subject with an extremely large number of publications and patents coming out year after year. It is impossible to do justice to this subject in a șhort overview. We, therefore, restrict ourselves to a few important developments in materials and processes relevant for capacitor applications. Here again, we have not attempted to cover barrier-layer capacitors since these are based on ferroelectric and non-ferroelectric materials as well and deserve a full article of present length.

\section{Barium titanate-based ceramic capacitors}

As is well known, $\mathrm{BaTiO}_{3}$ ceramics possess very high dielectric constant with relatively low dissipation factor. However, a severe limitation of this material in pure form for making capacitors is the high temperature coefficient of dielectric constant in the vicinity of the cubic to tetragonal phase transition. In this section, we discuss the two different strategies based on (i) grain refinement and (ii) solid solution formation which have been used to overcome this limitation. 


\subsection{Grain size effect in $\mathrm{BaTiO}_{3}$}

Undoped $\mathrm{BaTiO}_{3}$ ceramics with grain size $\sim 10 \mu \mathrm{m}$ usually possess a room temperature dielectric constant $\left(\varepsilon_{\mathrm{RT}}\right)$ of $\sim 2000$ and ubiquitous $90^{\circ}$ and $180^{\circ}$ domain structure (Jaffe et al 1971). $\varepsilon_{\mathrm{RT}}$ varies as a function of grain size. It can reach a maximum lying between 3000 and 5000 near $1 \mu$ grain size (Egerton and Koonce 1955; Kniepkamp and Heywang 1958; Brandmayr et al 1965; Kinoshita and Yamaje 1976). On the other hand, the peak dielectric constant at Curie point $\left(\varepsilon_{\max }\right)$ monotonically decreases with decreasing grain size below $5 \mu \mathrm{m}$ (see e.g. Vivekanandan et al 1986) reducing the temperature coefficient of dielectric constant near Curie point drastically. The grain size effect in $\mathrm{BaTiO}_{3}$ has been attributed to the near absence of $90^{\circ}$ domains in fine grain ( $\leqslant 1 \mu \mathrm{m}$ ) ceramics (Hutchins 1962) because of the significant thickness of $90^{\circ}$ walls $(0 \cdot 2$ to $0.4 \mu \mathrm{m})$ as compared to the grain size (Little 1955; Cooke et al 1966). The decreasing propensity of $90^{\circ}$ domains with grain size is believed to result in unrelieved stresses which accompany the cubic to tetragonal phase transition (Buessem et al 1966). These stresses are believed to suppress the spontaneous tetragonal deformation forcing the ceramic grains back towards the cubic state. However, the fact that even in loose powder form, XRD of fine $\mathrm{BaTiO}_{3}$ powders does not show tetragonal deformations at room temperature goes against the internal stress model. Unlike the fine grains in a sintered ceramic, these powders have got free surfaces to relieve any transformation strains whose accumulation in ceramic samples could otherwise suppress the tetragonal deformation.

While a more satisfactory explanation for the grain size effect in $\mathrm{BaTiO}_{3}$ is still awaited, the phenomenon is of great practical value. But to develop fine-grain ( $\leqslant 1 \mu \mathrm{m})$ $\mathrm{BaTiO}_{3}$ ceramics, one must start with ultrafine $\mathrm{BaTiO}_{3}$ powders which cannot be prepared by the conventional solid state route. Ultrafine $\mathrm{BaTiO}_{3}$ powders have been prepared by thermal decomposition of coprecipitated oxalates (Clabaugh et al 1956; Gallagher and Schrey 1963; Kiss et al 1966; Swilan and Gaddala 1973) and citrates (Mulder 1970; Kahn 1971; Hutchins et al 1987), thermal decomposition of metalorganic precursors (Mazdiyasni et al 1969; Mazdiyasni and Brown 1972; Shaikh and Vest 1986), sol-gel method (Diaz-Guemes et al 1989) and hydrothermal methods (Vivekanandan et al 1986).

The sintering of pure $\mathrm{BaTiO}_{3}$ powders obtained by dry or wet routes is usually performed at temperatures between $1300^{\circ}$ and $1400^{\circ} \mathrm{C}$ (Subbarao et al 1981). Depending on the sintering time, temperature and ambient, the average grain size is usually more than $10 \mu \mathrm{m}$ for highly dense ceramics because of extensive grain growth; this is irrespective of the particle size of the starting $\mathrm{BaTiO}_{3}$ powder. To prepare dense $\mathrm{BaTiO}_{3}$ ceramics with fine grain size, it is essential to inhibit grain growth which usually occurs above $1300^{\circ} \mathrm{C}$ in pure powders. Use of grain growth inhibitors such as $\mathrm{Nb}_{2} \mathrm{O}_{5}, \mathrm{Ta}_{2} \mathrm{O}_{5}, \mathrm{La}_{2} \mathrm{O}_{3}$, in excess of 0.3 at $\%$ and up to a few at $\%$, are recommended (Payne and Anderson 1967; Kahn 1971). The same dopants, when present in concentrations less than $0.3 \mathrm{at} \%$, promote grain growth and semiconductivity (Drofenik 1986). Kahn (1971) pointed out that the sintering atmosphere plays an important role. For example, reduced oxygen pressure in conjunction with moderate sintering temperatures allows the formation of small-grained $\mathrm{BaTiO}_{3}$ ceramics even when $\mathrm{Nb} \leqslant 0.3 \mathrm{at} \%$. On the other hand, $\mathrm{Nb} \geqslant 0.4 \mathrm{at} \%$ limits the grain size to $\leqslant 1 \mu \mathrm{m}$ under normal sintering in air. In principle, lowering the sintering temperature should also inhibit the grain growth and result in fine grain ceramics. However, liquid phase 
sintering, using $\mathrm{LiF}, \mathrm{BaLiF}_{3}$ and other similar fluxes, which can lower the sintering temperature by 400 to $500^{\circ} \mathrm{C}$, does not seem to give fine grain ceramics (see e.g. Desgardin et al 1985; Guha and Anderson 1986) unless a grain growth inhibitor is also used. According to a recent report by Armstrong et al (1990), fine grain $(<1.0 \mu \mathrm{m})$ $\mathrm{BaTiO}_{3}$ ceramics with near theoretical density can be prepared by sintering at temperatures $<1175^{\circ}$ for $2 \mathrm{~h}$ using $<2 \mathrm{vol} \%$ of a complex borate glass as flux and a $0.75 \mathrm{wt} \%$ of $\mathrm{ZrO}_{2}$ as grain growth inhibitor. As a result of lower sintering temperature, $\mathrm{Zr}^{4+}$, which usually diffuses onto $\mathrm{Ti}^{4+}$ sites above $1300^{\circ}$, resides at the grain boundary as $\mathrm{ZrO}_{2}$ and inhibits the grain growth. Fine grain size $\mathrm{BaTiO}_{3}$ ceramics have also been prepared by hot pressing of ultrafine $\mathrm{BaTiO}_{3}$ powders at low temperatures (Graham et al 1969; Okazaki and Takahashi 1970; Carry and Mocellin 1986). Graham et al (1969) reported nearly flat temperature response of dielectric constant for hot-pressed $\mathrm{BaTiO}_{3}$ ceramics. Application of hot pressing (HP), hot-isostatic pressing (HIP) and explosive sintering for developing fine grain $\mathrm{BaTiO}_{3}$ ceramics may be preferable as the use of grain growth inhibitors as well as the sintering aids often alter the dielectric response in an undesired fashion.

\subsection{Solid solution effect in $\mathrm{BaTiO}_{3}$}

A large number of cationic substitutions at $\mathrm{Ba}$ and Ti sites have been shown to broaden the temperature dependence of dielectric constant. Further these substitutions may also lower or raise the Curie point $\left(T_{c}\right)$. Both these properties have been commercially exploited.

Isovalent substitution of $\mathrm{Ba}$ by $\mathrm{Sr}, \mathrm{Pb}$ and $\mathrm{Ca}$ in the system $\mathrm{Ba}_{1-x} \mathrm{~A}_{x} \mathrm{TiO}_{3}(\mathrm{~A}=\mathrm{Sr}$, $\mathrm{Pb}$ and $\mathrm{Ca}$ ) has been studied by a large number of workers (Jaffe et al 1971). While $\mathrm{SrTiO}_{3}$ and $\mathrm{PbTiO}_{3}$ show complete solid solubility with $\mathrm{BaTiO}_{3}, \mathrm{CaTiO}_{3}$ shows solid solubility to a varying extent depending on temperature up to a maximum of $21 \mathrm{~mol} \%$ $\mathrm{CaTiO}_{3}$ under normal firing conditions. While $\mathrm{Sr}$ is known to lower $T_{c}$ at the rate of $-3.7^{\circ} \mathrm{C}$ per $\mathrm{mol} \%$ of $\mathrm{SrTiO}_{3}$ added, $\mathrm{Pb}$ monotonically raises $T_{c}$ towards that of $\mathrm{PbTiO}_{3}\left(490^{\circ} \mathrm{C}\right)$ at the same rate (for references see Jaffe et al 1971). Addition of $\mathrm{Sr}$ is known to gradually broaden the temperature dependence of dielectric constant besides raising the $\varepsilon_{\max }$ as compared to that of pure $\mathrm{BaTiO}_{3}$ (Smolensky and Rozgachev 1954). $\mathrm{Pb}$ substitution, on the other hand, lowers $\varepsilon_{\mathrm{RT}}$ as well as $\varepsilon_{\max }$ and does not seem to broaden the $\varepsilon$ vs $T$ curve (Shirane and Suzuki 1951). The most cited work on the effect of $\mathrm{Ba}$ substitution by $\mathrm{Ca}$ is by Mitsui and Westphal (1961) according to which $\mathrm{Ca}$ substitution affects $T_{c}$ only marginally with a shallow maximum for $8 \mathrm{at} \%$. The $\varepsilon_{\mathrm{RT}}$ is lowered by $\mathrm{Ca}$ substitution but $\varepsilon_{\max }$ remains almost comparable to that of pure $\mathrm{BaTiO}_{3}$.

Substitution of Ti by Sn (Smolensky and Isupov 1954; Schmidt 1990) or Zr (Kell and Hellicar 1956; Vivekanandan et al 1986) is also known to lower $T_{c}$ as well as make the phase transition diffuse. Substitutions at $\mathrm{Ba}$ as well as $\mathrm{Ti}$ sites have also been attempted for making the phase transition diffuse (see e.g. Yoon et al 1988). Offvalent substitutions are also known to cause diffuse phase transition (Parkash et al 1991).

Recent work in our laboratory has shown that the dielectric behaviour of $\mathrm{Ba}_{1-x} \mathrm{Ca}_{x} \mathrm{TiO}_{3}$ is very sensitive to the method of preparation. $\mathrm{Ba}_{1-x} \mathrm{Ca}_{x} \mathrm{TiO}_{3}$ ceramics prepared by using powders obtained using dry routes either by calcining a mixture of $\mathrm{BaCO}_{3}, \mathrm{CaCO}_{3}$ and $\mathrm{TiO}_{2}$ or by diffusion of $\mathrm{CaTiO}_{3}$ into $\mathrm{BaTiO}_{3}$ at high 


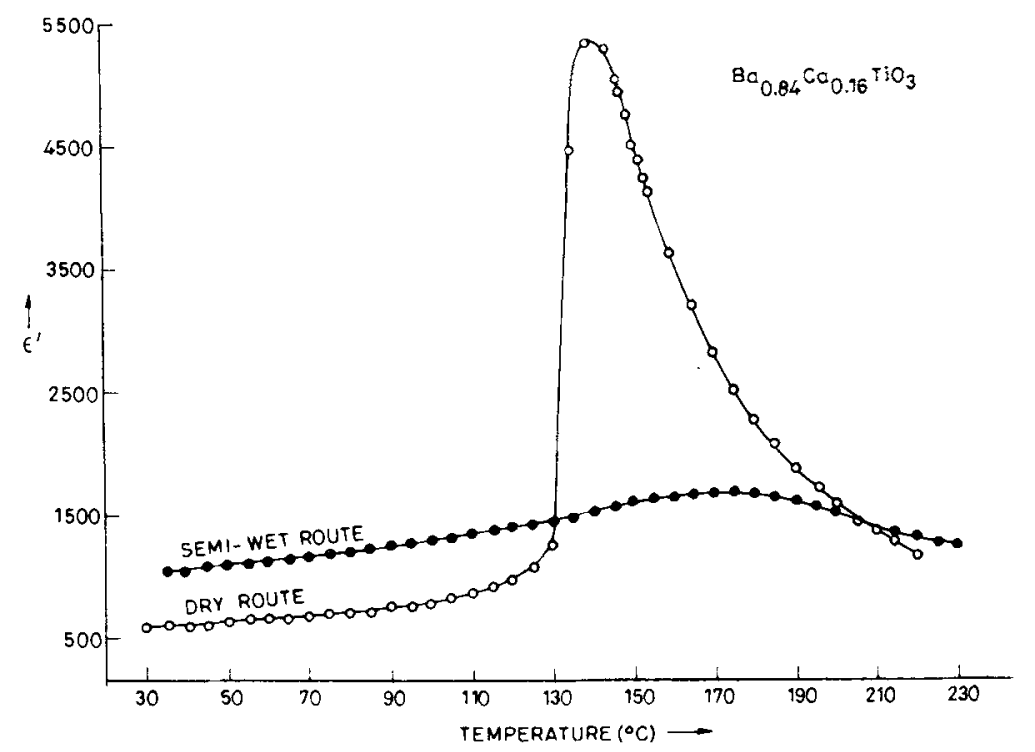

Figure 1. Temperature dependence of dielectric constant of $\mathrm{Ba}_{0.84} \mathrm{Ca}_{0.16} \mathrm{TiO}_{3}$ ceramics prepared by (a) semi-wet (O) and (b) dry (O) routes. Note the diffuse phase transition behaviour in the semi-wet sample. (After Tiwari and Pandey 1992).

temperatures, exhibit $\mathrm{BaTiO}_{3}$-like sharp transitions. The same ceramics when prepared from powders obtained by a semi-wet route involving calcination of $\mathrm{Ba}_{1-x} \mathrm{Ca}_{x} \mathrm{CO}_{3}$ solid solution precursors with $\mathrm{TiO}_{2}$ lead to a diffuse phase transition behaviour. The $\mathrm{Ba}_{1-x} \mathrm{Ca}_{x} \mathrm{CO}_{3}$ precursors were prepared by chemical coprecipitation and the solid solution formation was confirmed by XRD (Pandey et al 1987; Tiwari et al 1989). Figure 1 illustrates the difference in the temperature dependence of dielectric constant for $\mathrm{Ba}_{0.84} \mathrm{Ca}_{0.16} \mathrm{TiO}_{3}$ ceramics prepared by (i) using $\mathrm{Ba}_{0.84} \mathrm{Ca}_{0.16} \mathrm{CO}_{3}$ solid solution precursor (semi-wet route) and (ii) by the conventional dry route using $\mathrm{BaCO}_{3}, \mathrm{CaCO}_{3}$ and $\mathrm{TiO}_{2}$.

The diffuse phase transition (DPT) in mixed ferroelectric ceramics has been attributed by Smolensky (1970) to the presence of compositional inhomogeneities. We have compared the compositional homogeneity of $\mathrm{Ba}_{1-x} \mathrm{Ca}_{x} \mathrm{TiO}_{3}$ ceramics prepared by the semi-wet and dry routes using principles of line broadening analysis (Pandey et al 1989). Figure 2 depicts the plot of $\beta \cos \theta$ vs $\sin \theta$, where $\beta$ is the halfwidth of the pure diffraction profile and $\theta$, the Bragg angle for $\mathrm{Ba}_{0.88} \mathrm{Ca}_{0.12} \mathrm{TiO}_{3}$ samples. The nearly zero slope for the semi-wet sample confirms that it is compositionally homogeneous while the dry route sample is inhomogeneous. This rules out the possibility of DPT behaviour in semi-wet samples due to local compositional inhomogeneities.

On the basis of significant difference in the relative intensities of 200 and 002 reflections from the two types of powder samples, Tiwari et al (1989) proposed that $\mathrm{Ca}^{2+}$ might be going to both $\mathrm{Ba}^{2+}$ as well as $\mathrm{Ti}^{4+}$ sites because of ionic radius considerations in the conventional dry route of synthesis. This may in turn affect the nature of ferroelectric transition in these materials. It has been conjectured by several workers that $\mathrm{Ca}^{2+}$ can go to the $\mathrm{Ti}^{4+}$ site as well (Jaffe et al 1971; Han et al 1987). Recently, Tiwari et al (1991) determined the cation distribution in $\mathrm{Ba}_{0.88} \mathrm{Ca}_{0.12} \mathrm{TiO}_{3}$ samples prepared by semi-wet and dry routes using Rietveld profile 


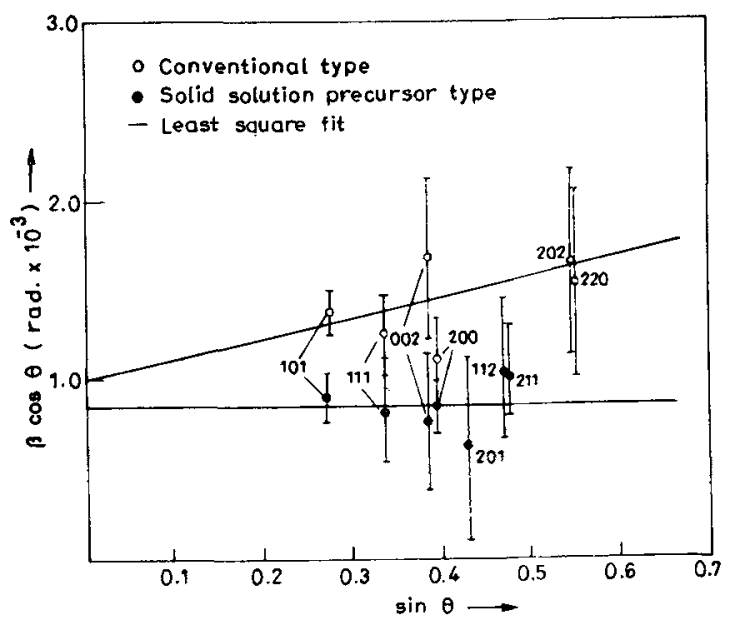

Figure 2. Comparison of compositional homogeneity of $\mathrm{Ba}_{0.88} \mathrm{Ca}_{0.12} \mathrm{TiO}_{3}$ powders prepared by (a) semi-wet $(O)$ and (b) dry (O) routes. Horizontal line indicates absence of compositional inhomogeneities. (After Pandey et ol 1989).

refinement of powder neutron diffraction patterrs. Neutron diffraction is eminently suited for exploring the possibility of $\mathrm{Ti}^{4+}$ getting substituted by $\mathrm{Ca}^{2+}$ since the atomic scattering factors for the two elements are of opposite signs. This study has clearly revealed that in powders obtained by the dry route, nearly half of the substituted $\mathrm{Ca}^{2+}$ occupies $\mathrm{Ti}^{4+}$ site in contrast to the semi-wet samples where all the $\mathrm{Ca}^{2+}$ ions exclusively occupy the $\mathrm{Ba}^{2+}$ site. The observed and calculated neutron diffraction patterns are in excellent agreement for both types of samples and are depicted along with the difference pattern in figure 3 . This study has revealed that the ferroelectric phase transition can get diffused in barium-calcium titanate system only if $\mathrm{Ca}^{2+}$ does not occupy $\mathrm{Ti}^{4+}$ site but exclusively replaces $\mathrm{Ba}^{2+}$ as in samples prepared by the semiwet route. This intrinsic effect of substitution of $\mathrm{Ba}^{2+}$ by $\mathrm{Ca}^{2+}$ on the nature of ferroelectric phase transition gets masked in the conventional dry route of synthesis as a result of mixed occupancy of $\mathrm{Ca}^{2+}$ at $\mathrm{Ba}^{2+}$ as well as $\mathrm{Ti}^{4+}$ sites leading to the sharp transition.

Apart from better compositiona homogeneity and a control over the sitesubstitution, Tiwari et al (1989) have shown using DTA study of solid state thermochemical reaction in mixtures containing (i) $\mathrm{Ba}_{0.9} \mathrm{Ca}_{0.1} \mathrm{CO}_{3}$ and $\mathrm{TiO}_{2}$ (semi-wet route) and (ii) $\mathrm{BaCO}_{3}, \mathrm{CaCO}_{3}$ and $\mathrm{TiO}_{2}$ that the reaction temperature is nearly $150^{\circ} \mathrm{C}$ lower for the semi-wet route (see figure 4). Further, ceramics prepared using powders obtained by the semi-wet route show very uniform microstructure with average grain size $\leqslant 1 \mu \mathrm{m}$ (see figure $5 \mathrm{a}$ ), depending on the $\mathrm{Ca}^{2+}$ content, and density above $95 \%$ of the theoretical value for sintering at $1300^{\circ}$ for $12 \mathrm{~h}$. Ceramics sintered under identical conditions using powders obtained by the conventional route have grain size $\gtrsim 5 \mu \mathrm{m}$ and densities never exceeding $90 \%$ (see figure $5 \mathrm{~b}$ ).

In order to compare the effect of substitution of $\mathrm{Ba}^{2+} \mathrm{by}^{2+} \mathrm{Sb}^{2+} \mathrm{Sr}^{2+}$ and $\mathrm{Ca}^{2+}$ on the dielectric behaviour, we have prepared compositionally homogeneous fine-grained $\left(\sim 1 \mu \mathrm{m}\right.$ grain size) $\mathrm{Ba}_{0.92} \mathrm{~A}_{0.08} \mathrm{TiO}_{3}(\mathrm{~A}=\mathrm{Pb}, \mathrm{Sr}$ and $\mathrm{Ca})$ ceramics under identical calcination and sintering conditions using our semi-wet approach. The 002 and 200 reflections for the three samples are given in figure 6 which shows that the $c$-parameter 

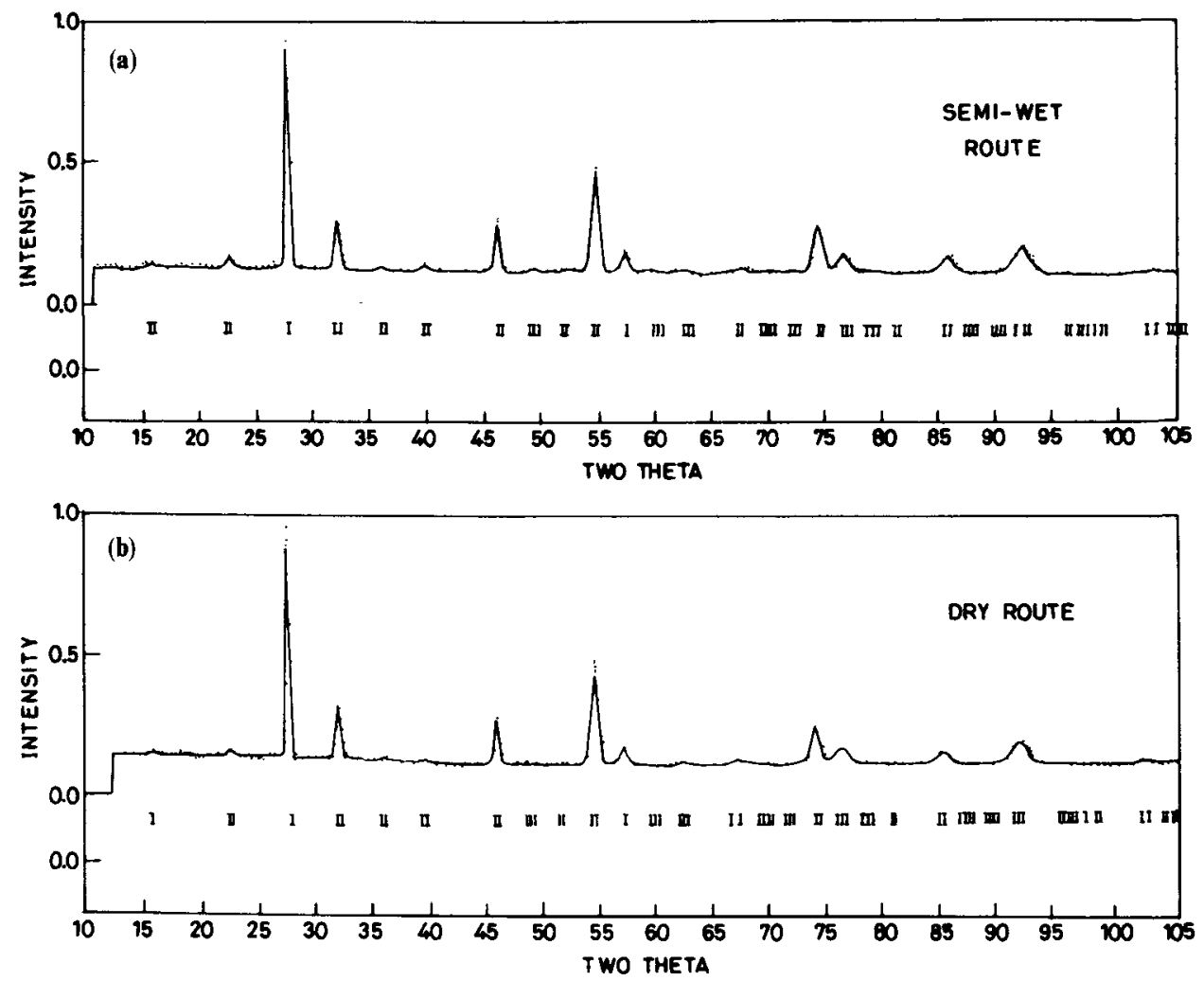

Figure 3. Results of Rietveld profile analysis of neutron diffraction data of (a) semi-wet and (b) dry route samples of barium-calcium titanate with nominal composition $\mathrm{Ba}_{0.88} \mathrm{Ca}_{0.12} \mathrm{TiO}_{3}$. (After Tiwari et al 1991).

gradually increases with $\mathrm{Ca}, \mathrm{Sr}$ and $\mathrm{Pb}$ substitutions. Figure 7 depicts the temperature dependence of dielectric constant for the three compositions. It is evident that maximum diffuseness is observed for $\mathrm{Ca}^{2+}$ substitution followed by $\mathrm{Pb}^{2+}$ and $\mathrm{Sr}^{2+}$. It is important to reiterate that the diffuseness of phase transition in these samples is not due to local compositional inhomogeneities as the $\mathrm{X}$-ray line broadening analysis has shown these samples to be compositionally homogeneous (Tiwari and Pandey (to be published); Singh et al (to be published)). Although all the three samples exhibit DPT, each one of the three systems has got its unique characteristic frequency response, the details of which will be published separately in due course.

\section{Relaxor ferroelectric ceramics}

The maximum dielectric constant for modified $\mathrm{BaTiO}_{3}$ lies in the range 10,000 to 14,000 . With continuing trend for miniaturization of single/multi-layer capacitors, the attention has shifted towards a new class of lead based complex ferroelectric ceramics, typified by $\mathrm{Pb}\left(\mathrm{B}_{1 / 3}^{\prime} \mathrm{B}_{2 / 3}^{\prime \prime}\right) \mathrm{O}_{3}$ (where $\mathrm{B}^{\prime}=\mathrm{Mg}^{2+}, \mathrm{Zn}^{2+}, \mathrm{Ni}^{2+}$ etc. and $\mathrm{B}^{\prime \prime}=\mathrm{Nb}^{5+}, \mathrm{Ta}^{5+}$ etc.) and $\mathrm{Pb}\left(\mathrm{C}_{1 / 2}^{\prime} \mathrm{C}_{1 / 2}^{\prime \prime}\right) \mathrm{O}_{3}$ (where $\mathrm{C}^{\prime}=\mathrm{Sc}^{3+}, \mathrm{Fe}^{3+}, \mathrm{In}^{3+}$ etc. and $\mathrm{C}^{\prime \prime}=\mathrm{Nb}^{5+}, \mathrm{Ta}^{5+}$ etc), with peak dielectric constant in the range 15,000 to 30,000 (Shrout and Halliyal 1987). 

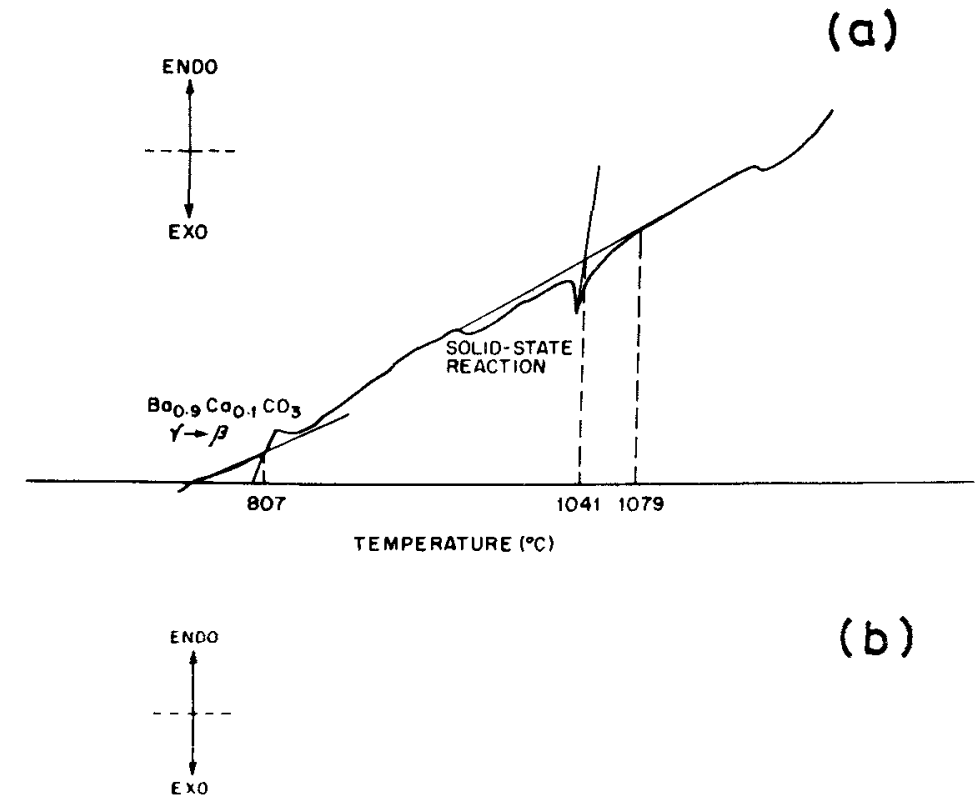

(b)

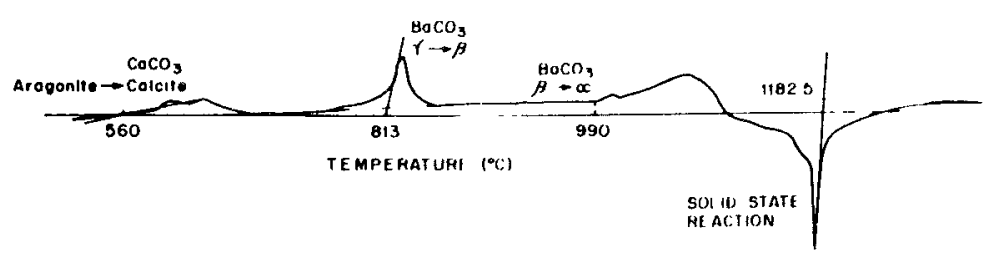

Figure 4. DTA of solid state thermochemical reaction in a mixture of (a) $\mathrm{Ba}_{0.9} \mathrm{Ca}_{0.1}$ $\mathrm{CO}_{3}+\mathrm{TiO}_{2}$ (semi-wet route) and (b) $0.9 \mathrm{BaCO}_{3}+0 \cdot 1 \mathrm{CaCO}_{3}+\mathrm{TiO}_{2}$ (dry route). (After Tiwari et al 1989).

All these materials exhibit diffuse phase transition in both single crystal as well as sintered ceramic forms (Smolensky 1970) with pronounced characteristic frequency response in the audio frequency region (Cross 1987). The peaks corresponding to $\varepsilon_{\max }^{\prime}$ and $\varepsilon_{\max }^{\prime \prime}$ in these materials shift to higher temperature side on increasing the measuring frequency. These materials are accordingly called relaxor ferroelectrics (Cross 1987). The DPT behaviour and the relaxor behaviour disappears if the $\mathrm{B}^{\prime}, \mathrm{B}^{\prime \prime}$ or $\mathrm{C}^{\prime}, \mathrm{C}^{\prime \prime}$ ions acquire ordered configuration to minimize the electrostatic and elastic energies (Setter and Cross 1980). We would like to mention that relaxor behaviour is observed in $\mathrm{Ba}_{1-x} \mathrm{Sr}_{x} \mathrm{TiO}_{3}$ and $\mathrm{BaTi}_{1-x} \mathrm{Sn}_{x} \mathrm{O}_{3}$ also (Schmidt 1990; Tiwari and Pandey (to be published)). Some of the lead-based complex ferroelectrics when mixed with $\mathrm{PbTiO}_{3}, \mathrm{BaTiO}_{3}$ etc. show interesting dielectric behaviour including the enhancement of $\varepsilon^{\prime}$ in the vicinity of a morphotropic phase boundary composition akin to that in PZT ceramics (Kuwata et al 1982; Halliyal et al 1987). Relaxor compositions for capacitor applications are usually solid solutions with one end member being a $T_{c}$ shifter that adjusts the dielectric maximum closer to room temperature to meet the Z5U, Y5V and Y5S standard specifications.

Despite the advantages associated with high dielectric constant and low sintering temperatures, there are a few disadvantages of the relaxor materials such as (i) strong 

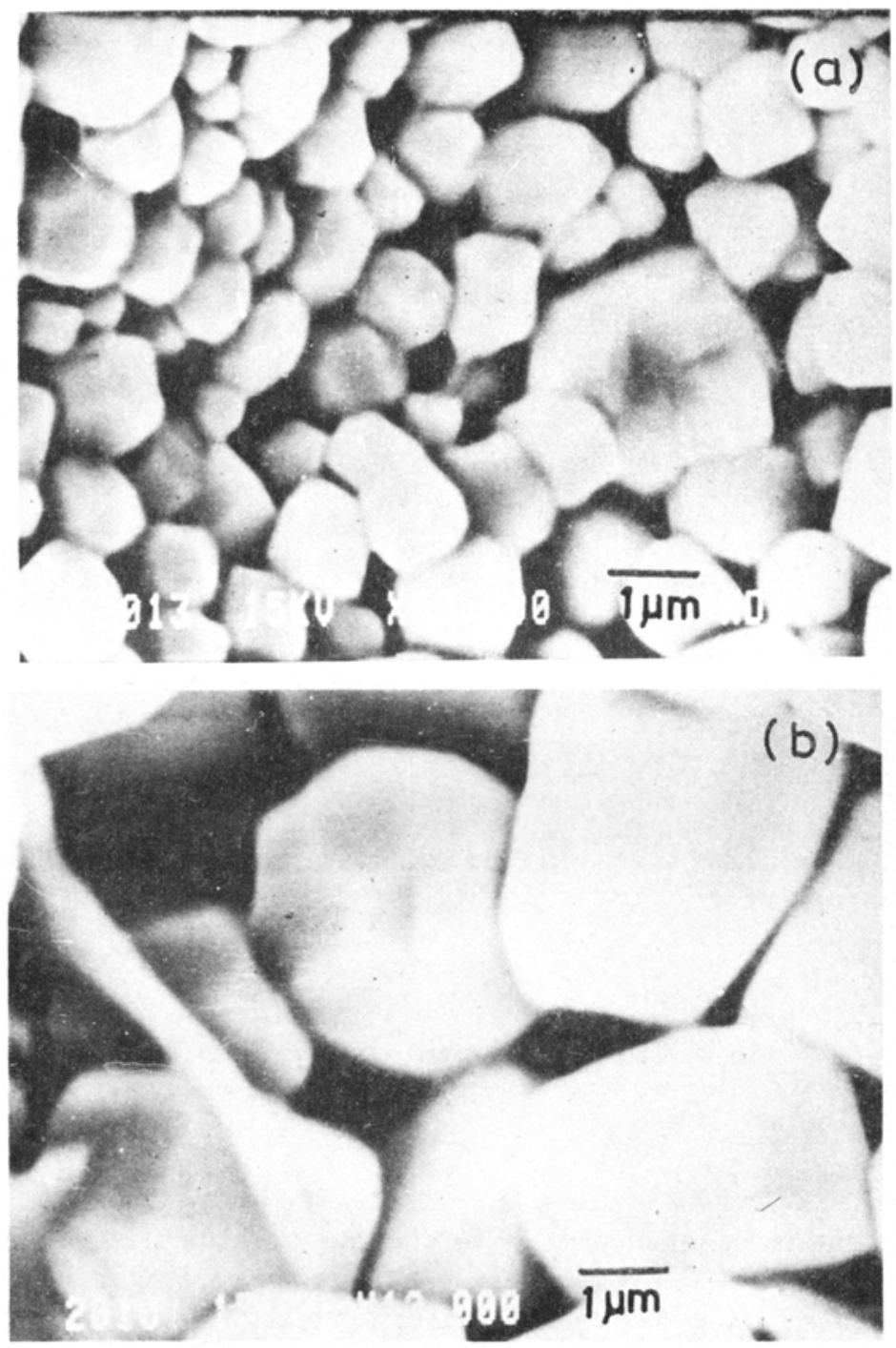

Figure 5. Microstructure of $\mathrm{Ba}_{0 \cdot 88} \mathrm{Ca}_{0 \cdot 12} \mathrm{TiO}_{3}$ ceramics prepared by (a) semi-wet and (b) dry routes (After Tiwari and Pandey 1992).

frequency dependence with high dielectric losses, (ii) low mechanical strength, (iii) toxic nature of $\mathrm{PbO}$ which is the major constituent and (iv) difficult to get in single phase form free from the pyrochlore phase. Swartz and Shrout (1982) could overcome the last problem by eliminating the formation of the intermediate pyrochlore phases. This was achieved by first forming a Columbite $\mathrm{MgNb}_{2} \mathrm{O}_{6}$ matrix via solid state reaction between $\mathrm{MgO}$ and $\mathrm{Nb}_{2} \mathrm{O}_{5}$ around $1000^{\circ} \mathrm{C}$. This columbite was then reacted in the solid state with $\mathrm{PbO}$ around $700^{\circ} \mathrm{C}$ to yield pure $\mathrm{PbMg}_{1 / 3} \mathrm{Nb}_{2 / 3} \mathrm{O}_{3}$ free from pyrochlore phase. The same approach has been employed by Groves (1985) to synthesise $\mathrm{PbIn}_{1 / 2} \mathrm{Nb}_{1 / 2} \mathrm{O}_{3}$ with limited success. For $\mathrm{PbZn}_{1 / 3} \mathrm{Nb}_{2 / 3} \mathrm{O}_{3}(\mathrm{PZN})$, this approach is not at all successful. PZN by far remains the most difficult relaxor material to 


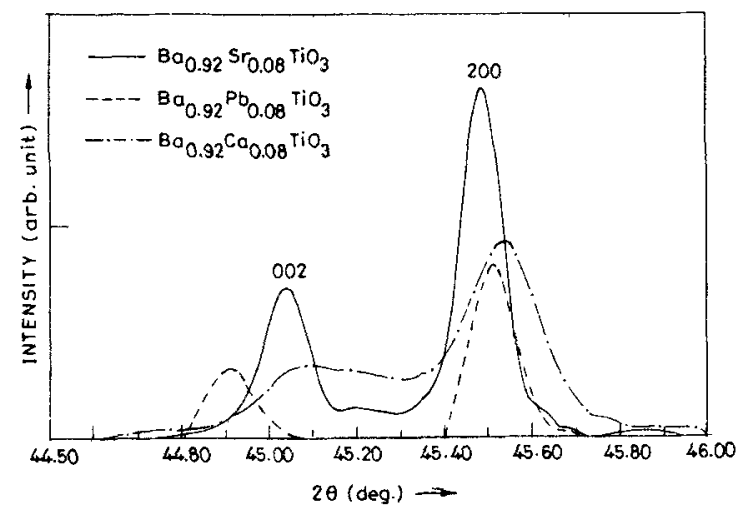

Figure 6. 002 and 200 reflections of (a) $\mathrm{Ba}_{0.92} \mathrm{Sr}_{0.08} \mathrm{TiO}_{3}$, (b) $\mathrm{Ba}_{0.92} \mathrm{~Pb}_{0.08} \mathrm{TiO}_{3}$ and (c) $\mathrm{Ba}_{0.92} \mathrm{Ca}_{0.08} \mathrm{TiO}_{3}$ powders prepared by semi-wet route (After Singh et al 1992). $\mathrm{CuK}_{z}$ radiation.

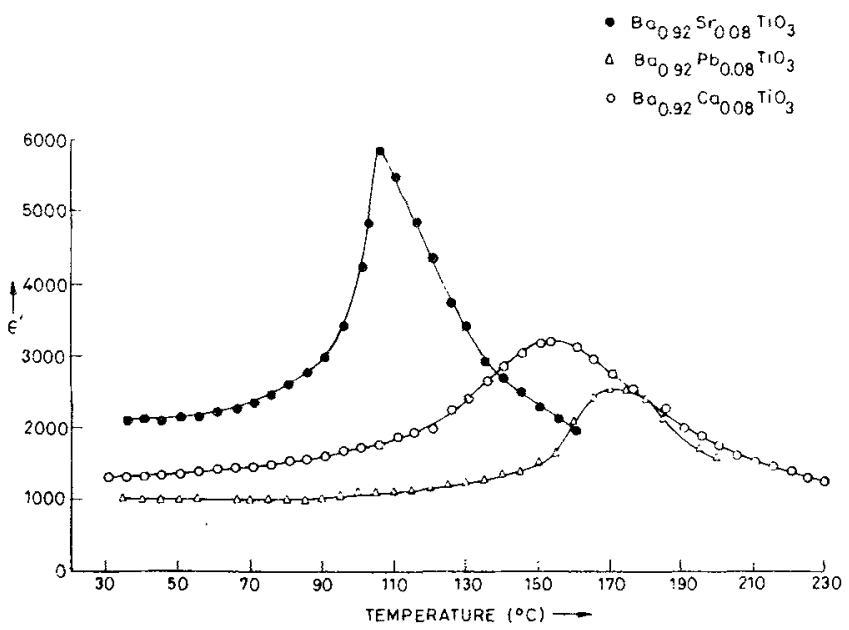

Figure 7. Temperature dependence of dielectric constant $(100 \mathrm{kHz})$ of (a) $\mathrm{Ba}_{0.92} \mathrm{Sr}_{0.08} \mathrm{TiO}_{3}$, (b) $\mathrm{Ba}_{0.92} \mathrm{~Pb}_{0.08} \mathrm{TiO}_{3}$ and (c) $\mathrm{Ba}_{0.92} \mathrm{Ca}_{0.08} \mathrm{TiO}_{3}$ ceramics prepared by semi-wet route (After Singh et al 1992).

synthesize in pure form. Addition of 6 to $7 \mathrm{~mol} \%$ of barium titanate has been shown to have resulted in single phase PZN (Furukawa et al 1985). There are already quite a few US patents for ceramic capacitors based on relaxor ferroelectrics.

\section{Multilayer capacitors}

The continuing trend towards miniaturization of electronic integrated circuits has led to considerable spurt in the multilayer ceramic capacitor (MLC) industry. Until recently, modified $\mathrm{BaTiO}_{3}$ has been the main material for making these MLCs. This requires high firing temperatures in excess of $1300^{\circ} \mathrm{C}$. Obviously, the materials used for inner electrodes should have higher melting points than the sintering temperature of the dielectric ceramics. To avoid oxidation of the inner electrodes during co-firing in 
air, it is imperative to use precious metals such as Pd and Pt. Several different strategies have accordingly been adopted to reduce the cost of these MLCs (see e.g. Goodman 1986). These include using inexpensive $\mathrm{Ag}-\mathrm{Pd}$ alloy (m.p. 1220 for $70 / 30$ composition) along with sintering fluxes to lower the firing temperature (see $\$ 2$ ). The second approach is the lead injection method in which molten lead is impregnated into the porous layer to form the inner electrode. The third strategy, which seems to receive maximum attention, is the use of low cost base metals, such as $\mathrm{Cu}, \mathrm{Ni}$ and $\mathrm{Fe}$, as internal electrode material. Use of base metals necessitates co-firing in a reducing atmosphere since these metals loose their conductivity on being oxidized at high sintering temperatures in air. Co-firing in reducing atmosphere, on the other hand, gives rise to $n$ type semiconductivity since $\mathrm{BaTiO}_{3}$ based materials loose oxygen under reducing atmosphere. For dielectric applications, one needs not only high dielectric constant but also high DC blocking resistance. There has been a lot of work on the effect of doping by acceptor type ions (e.g. $\mathrm{Co}, \mathrm{Cr}, \mathrm{Fe}, \mathrm{Mn}, \mathrm{Ga}$ and $\mathrm{Ni}$ ) on the dielectric behaviour and DC resistance of the ceramic MLCs co-fired with $\mathrm{Ni}$ electrodes in reducing atmosphere (Herbert 1965; Burn 1979; Hagemann and Iring 1979; Desu and Subbarao 1981). As a result of acceptor doping, it has been possible to co-fire the Ni-electrodes with the ceramic dielectric at low oxygen partial pressures without losing the insulating behaviour of the dielectric.

Recently, a ceramic dielectric composition for MLCs that can be co-fired with Ni electrode was reported by Sakabe (1987). The general composition is $\left\{\left(\mathrm{Ba}_{1-x} \mathrm{Ca}_{x}\right) \mathrm{O}\right\}_{m}$ $\left\{\left(\mathrm{Ti}_{1-y} \mathrm{Zr}_{y}\right) \mathrm{O}_{2}\right\}$ and is effective only when $0 \leqslant x \leqslant 0.2$ and $1.0005 \leqslant m \leqslant 1.030$. The role of $\mathrm{Zr}$ in this composition is essentially as a Curie point shifter to bring the maximum dielectric constant at the operating temperature. The most interesting aspect of this composition is the fact that $(\mathrm{Ba}+\mathrm{Ca})>(\mathrm{Ti}+\mathrm{Zr})$. It was conjectured by Sakabe (1987) that for $m>1, \mathrm{Ca}^{2+}$ can partially occupy the $\mathrm{Ti}^{4+}$ site because of ionic size considerations and thereby act as an acceptor impurity. This in turn facilitates the co-firing of the ceramic dielectric with $\mathrm{Ni}$ electrode without reducing the dielectric composition. This has indeed been confirmed by Han et al (1987) through equilibrium conductivity measurements. It may be recalled from $\$ 2 \cdot 2$ that our recent neutron scattering work on $\mathrm{Ba}_{1-x} \mathrm{Ca}_{x} \mathrm{TiO}_{3}$ ceramics prepared by the conventional dry route has revealed the presence of $\mathrm{Ca}^{2+}$ at $\mathrm{Ti}^{4+}$ site.

The capacitance per unit volume or packing density is approximately proportional to the dielectric constant and inversely proportional to the thickness of the active dielectric in a MLC. To improve the compactness of the $\mathrm{BaTiO}_{3}$-based MLCs, lowest achievable thicknesses lie typically in the range of 15 to $35 \mu \mathrm{m}$. Any further improvement in the compactness of the MLCs has to depend on new materials with dielectric constant higher than that of modified $\mathrm{BaTiO}_{3}$. Relaxor ferroelectric ceramics have opened new hopes in improving the compactness of MLCs by virtue of their extremely high dielectric constant in the range 15,000 to 30,000 as against 10,000 to 14,000 for modified $\mathrm{BaTiO}_{3}$. These new materials can be sintered at low temperatures $\left(\sim 900^{\circ} \mathrm{C}\right)$ and therefore obviate the necessity of expensive electrode metals. Future trend is therefore going to be in the development of MLCs based on relaxor ferroelectrics although $\mathrm{BaTiO}_{3}$-based single- and multi-layer capacitors will continue to receive worldwide attention because of their better frequency response and lower loss factors. 


\section{References}

Armstrong T, Young K A and Buchanan R C $1990 \mathrm{~J}$. Am. Ceram. Soc. 73700

Brandmayr R J, Brown A E and Dunlap A M 1965 NASA Accession No. N66-14809, Rept. No. ECOM-2614

Buessem W R, Cross L E and Goswami A K 1966 J. Am. Ceram. Soc. 4933

Burn I 1979 J. Mater. Sci. 142453

Carry C and Mocellin A $1986 \mathrm{~J}$. Am. Ceram. Soc. 69 C-215

Clabaugh W S, Swiggard E M and Gilchrist R 1956 J. Res. Nat. Bur. Std. 56289

Cooke F W, Bradt R C, DeVries R. C and Ansell G S 1966 J. Am. Ceram. Soc. 49648

Cross L E 1987 Ferroelectrics 76241

Desgardin G, Mey Isabelle, Raveau B and Haussonne J M 1985 Am. Ceram. Soc. Bull. 64564

Desu S B and Subbarao E C 1981 in Advances in ceramics (ed.) L M Levinson (Columbus: American Cer. Soc.) vol. I, p. 189

Diaz-Guemes M I, Carreno T G, Serna C J and Palacios J M 1989 J. Mater. Sci. 241011

Drofenik M H 1986 J. Am. Ceram. Soc. 69 C-8

Egerton L and Koonce S E 1955 J. Am. Ceram. Soc. 38412

Furukawa O, Yamashita Y, Harata M, Takahashi T and Inagaki K 1985 Jpn. J. Appl. Phys. 2496

Gallagher P K and Schrey F 1963 J. Am. Ceram. Soc. 46567

Goodman G 1986 in Ceramics for electronic applications, (ed.) R C Buchanan (New York: Marcel Dekker) p. 90

Graham H C, Tallan N M and Mazdiyasni K S 1969 J. Am. Ceram. Soc. 52548

Groves P 1985 Ferroelectrics 6567

Guha J P and Anderson H U $1986 \mathrm{~J}$. Am. Ceram. Soc. 69 C-193

Hagemann H J and Iring H 1979 Phys. Rev. B20 3871

Halliyal A, Kumar U, Newnham R E and Cross L E 1987 J. Am. Ceram. Soc. 70119

Han Y H, Appleby J B and Smyth D M 1987 J. Am. Ceram. Soc. 7096

Herbert J M 1965 Proc. IEEE 1121474

Hutchins G 1962 (Private Communication) Cited in Buessem et al (1966)

Hutchins G A. Maher G H and Ross S D 1987 Am. Ceram. Soc. Bull. 66681

Jaffe B, Cook W R and Jaffe H 1971 in Piezoelectric ceramics (New York: Academic Press)

Kahn M 1971 J. Am. Ceram. Soc. 54452

Kell R C and Hellicar N I 1956 Acoustica 6235

Kinoshita K and Yamaji A $1976 J$. Appl. Phys. 47371

Kiss K, Magder J, Vukasovich M S and Lockhart R J 1966 J. Am. Ceram. Soc. 49291

Kniepkamp H and Heywang W 1954 Z. Angew. Phys. 6 385; 1958 Ger. Patent 969037

Kuwata J, Uchino K and Nomura S 1982 Jpn. J. Appl. Phys. 211298

Little E A 1955 Phys. Rev. 98978

Mazdiyasni K S and Brown L H 1971 J. Am. Ceram. Soc. 54539

Mazdiyasni K S and Brown L H 1972 J. Am. Ceram. Soc. 55 541, 633

Mazdiyasni K S, Deloff R T and Smith J S 1969 J. Am. Ceram. Soc. 52523

Mitsui T and Westphal W B 1961 Phys. Rev. 1241354

Mulder B J 1970 Am. Ceram. Soc. Bull. 49990

Okazaki K and Takahashi K 1970 J. Phys. Soc. Jpn. Suppl. 28328

Pandey D, Tiwari V S, Singh T B, Pandey L, Parke h O and Ramachandrarao P 1987 Phase Trans. 911

Pandey D, Tiwari V S, Singh A K and Chaudhry S 1989 Bull. Mater. Sci. 12245

Parkash Om, Prasad C D and Kumar D 1990 J. Mater. Sci. 25487

Payne D A and Anderson H U 1967 J. Am. Ceram. Soc. 50 491

Sakabe Y 1987 Ceram. Bull. 661388

Schmidt G 1990 Phase Trans. 20127

Setter N and Cross L E 1980 J. Appl. Phys. 514356

Shaikh A and Vest M $1986 \mathrm{~J}$. Am. Ceram. Soc. 69682

Shirane G and Suzuki K 1951 J. Phys. Soc. Jpn. 6274

Shrout T R and Halliyal A 1987 Am. Ceram. Soc. Bull. 66704

Singh A P, Tiwari V S and Pandey D 1992 to be published

Smolensky G A 1970 J. Phys. Soc. Jpn. 28 Suppl. 26 
Smolensky G A and Isupov V A 1954 Zh. Tech. Fiz. 241375 (in Russian)

Smolensky G A and Rozgachev K I 1954b Zh. Tekhn. Fiz. 241751 (in Russian)

Subbarao E C, Prasad V C S and Rao K V 1981 in Preparation and characterization of materials, (eds) J M Honig and C N R Rao, (New York: Academic Press) p. 217

Swartz S L and Shrout T R 1982 Mater. Res. Bull. 171245

Swilan M N and Gaddala A M 1973 J. Brit. Ceram. Soc. 74159

Tiwari V S, Groves P and Pandey D 1989 J. Phys. D22 837

Tiwari V S and Pandey D 1992 To be published

Tiwari V S, Pandey D, Krishna P S R. Chakravorthy R and Dasannacharya B A 1991 Physica B 174112

Vivekanandan R, Philip S and Kutty T R N 1986 Mater. Res. Bull. 2299

Yoon K H. Kim J H, Jo K H, Song H I. Yoon S O and Kim C S 1988 J. Mater. Sci. 2361 